\title{
Evolution of Provincial Economic and Social Development Plan for Pandemic Prevention since SARS to COVID-19
}

He LI, Japan

\begin{abstract}
After the SARS outbreak of 2003, what had changed in China's economic and social development plan? Moving into the CODIV-19 era, has any innovation taken place in the latest development plan covering the period from 2021 to 2025? This paper attempts to explore answers to the above questions. This study looks at the 31 provinces, municipalities, and autonomous regions in mainland China. 114 files of the $10^{\text {th }}(2001-2005), 11^{\text {th }}(2006-2010), 12^{\text {th }}(2011-2015), 13^{\text {th }}(2016$ 2020), and $14^{\text {th }}$ (2021-2025) Five-Year Plan for provincial Economic and Social Development were collected. Totally, more than 6 million words. Text analysis was applied as the research method in the study. Specifically, it is the term frequency analysis. Firstly, the vocabulary about pandemic prevention was based on 114 files; then compared the changes of term frequency over years to summarise the evolution of Provincial Economic and Social Development Plan. Main findings: the system of China's modern public health emergency management started since SARS with a leapfrog development while became comprehensive during the COVID-19 outbreak; The economic policies released during COVID-19 proposed various financial and banking supports and aid. It is likely to have a profound effect on the future.
\end{abstract}

\section{Keywords}

Provincial Economic and Social Development Plan, Content analysis, Pandemic Prevention

\section{Introduction}

The 2002-2003 outbreak of severe acute respiratory syndrome (SARS) have challenged China's public health emergency management system (PHEMS) critically(Sun et al., 2018). 17 years have passed, COVID19 has been challenging the PHEMS once again(Wang et al., 2020).

Over the past nearly two decades, Chinese government has taken forceful actions to build PHEMS(Sun et al., 2018), urban and rural space with health service function was getting more and more attentions(Songlin et al., 2020, Yun and Yu, 2011, Yin et al., 2010), the country has experienced rapid economic growth(Zhang et al., 2021); on the other hand, the rapid economic growth and progress has not been matched by progress in health care(Wang, 2017), the development level of medical and health services is uneven among regions(Pan and Zhu, 2020, LIANG et al., 2019), and the characteristics of the two outbreaks are different(Hu et al., 2021, Yang et al., 2020). So that such a difficult situation is not unexpected. Different anti-epidemic situations must give rise to new anti-epidemic strategies, no matter long-term or emergency, whether at the macro or micro level. This study aims to figure out what's new of the long-term pandemic prevention measures at the macro level. 
Outline of Five-Year Plan for provincial economic and social development is one of the most important upper-level plans for city comprehensive planning. It also can reflect the overall situation in the country in a more comprehensive way. It is released every five years by local governments of the Communist Party of China. It is a series of social and economic development initiatives and often referred to as Fiveyear Plan. Based on Five-year Plans of the past 20 years and the next 5 years of 31 provinces, municipalities, and autonomous regions apply text analysis to explore the evolution of long-term pandemic prevention measures at the macro level is feasible and valuable.

The introduction is followed by a brief literature review summarised two types of related research; the next section is to state the methodology and data processing; then it is the core of this study, including the main analysis results; in the last part, the main findings were summarised, the flaws and the future improvement strategies were proposed.

\section{Literature review}

Recently, many studies have emerged on emergency anti-epidemic measures. Wu et al. (2021) applied Bibliometric methods on 366 policies of epidemic prevention during COVID-19 to reveal and characterize the patterns of China's anti-pandemic policy and the evolution over time. Chinazzi et al. (2020)aimed to figure out the impact of travel restrictions in Wuhan City on the national and international spread of the epidemic by using quantitative analysis method. Evenett (2020) used qualitative analysis method to characterize and assess current trade policy stance towards the imported goods used by hospitals and front-line medical professionals to tackle COVID-19 in multiple countries.

Related to long-term pandemic prevention measures, there are significant portion of the research has focused on healthy cities. Ran et al. (2021) compared several subjective and objective methods to find out an appropriate evaluation method for evaluating the level of healthy city by taking cities in Central China as study cases. Li et al. (2020) used Experts Grading Method to develop a scientific and appropriate indicator system for the evaluation of a healthy city in Chongqing, China. Webster and Sanderson (2013) provided an important insight into the interpretation, availability, and feasibility of collecting data, resulting in the development of a revised set of 32 indicators with improved definitions. Besides, there are also articles about urban and rural green space with health service function. Wolch et al. (2014) reviewed the Anglo-American literature on urban green space, especially parks, and compares efforts to green US and Chinese cities and proposed that urban planners, designers, and ecologists need to focus on urban green space strategies that are "just green enough "and that explicitly protect social as well as ecological sustainability.

Above mentioned related research have important reference value for building the vocabulary applied in this study.

\section{Methodology and data processing}

\subsection{Methodology and text analysis tool}

Word frequency, which refers to the number of times a given word appears in that document. It is a common weighting technique used in intelligence retrieval and text mining to evaluate the degree of repetition of a word for a document or a set of domain documents in a corpus. The importance of a word increases proportionally with the number of times it appears in a document. Higher frequency means higher concern. Changes in frequency mean shifts in focus. Differences among different period Five-year Plans can reveal the policy trends.

Gooseeker is a text analysis tool with word frequency analysis function. The tool is based on machine learning algorithms for Chinese word segmentation. And it allows user to combine words with the same 
meaning into one term for analysis. To compare with other text analysis tools, it has been proven to be effective in word frequency analysis (Tao et al., 2019, Tao et al., 2021).

\subsection{Data processing}

The 2002-2003 outbreak of SARS occurred during Tenth Plan (2001-2005) and Covid-19 occurred during Thirteenth Plan (2016-2020). To figure out how the public health emergencies effect the policy decision, this study used the text of Tenth Plan (2001-2005), Eleventh Plan (2006-2010), Twelfth Plan (20112015), Thirteenth Plan (2016-2020) and Fourteenth Plan (2021-2025) as the data basis for content mining.

There are 31 Provincial administrative units in mainland China. Finally, 31 files of Tenth Plan, 16 files of Eleventh Plan, 17 of Twelfth Plan, 21 of Thirteenth Plan, 29 of Fourteenth Plan are collected. All of them are downloaded from government official website. Totally, there are 114 files, more than 6 million words. As shown in Table.1.

\begin{tabular}{cccccccc}
\hline & & $\begin{array}{c}\text { Tenth Plan } \\
(2001-2005)\end{array}$ & $\begin{array}{c}\text { Eleventh Plan } \\
(2006-2010)\end{array}$ & $\begin{array}{c}\text { Twelfth Plan } \\
(2011-2015)\end{array}$ & $\begin{array}{l}\text { Thirteenth } \\
(2016-2020)\end{array}$ & $\begin{array}{l}\text { Plan } \\
(2021-2025)\end{array}$ \\
\hline \multirow{2}{*}{$\begin{array}{c}\text { Total } \\
\text { Number }\end{array}$} & $\begin{array}{c}\text { Words } \\
\text { in text }\end{array}$ & 31 & 16 & 17 & 21 & 29 \\
\hline
\end{tabular}

Table 1. Total Number of Files and Words. Source: Author.

To conduct the content analysis on files of Five-year Plans by using Gooseker, it is necessary to preprocess the files as following: convert file format to adapt the analysis tool; delete the pictures and nontext content. Then, import the pre-processed files into the analysis tool. Based on the word segmentation result of the tool and its function of merging synonyms, referring to related studies, establish a vocabulary with the theme of anti-epidemic measures. As shown in Table 2. Then export the term frequency statistics of selected words for further analysis

\begin{tabular}{|c|c|c|}
\hline Health care & Infectious disease & Interest discount and tax benefits \\
\hline Emergency & Mental health & Physical condition \\
\hline Sports & Sports facilities & Maternal \\
\hline Children & Disease Control and Prevention & Medium or long-term loans \\
\hline Public health & Living space & Reduce rent and interest \\
\hline Disable people & Wastes treatment & Fever clinics \\
\hline Pandemic & Vaccine & Emergency transportation \\
\hline Park & Non-motorized traffic & Stabilize posts \\
\hline Online & Public transportation & Service in foreign languages \\
\hline Medical supplies & Health education & SARS \\
\hline The elderly & & \\
\hline
\end{tabular}

Table 2. vocabulary with the theme of anti-epidemic measures 


\section{Analysis results and discussion}

\subsection{Analysis results}

\begin{tabular}{|c|c|c|c|c|c|c|c|c|c|c|}
\hline \multirow{2}{*}{$\begin{array}{c}\text { Rank } \\
\text {-ing }\end{array}$} & \multicolumn{2}{|c|}{$\begin{array}{l}\text { Tenth Plan } \\
\text { (2001-2005) }\end{array}$} & \multicolumn{2}{|c|}{$\begin{array}{l}\text { Eleventh Plan } \\
(2006-2010)\end{array}$} & \multicolumn{2}{|c|}{$\begin{array}{l}\text { Twelfth Plan } \\
\text { (2011-2015) }\end{array}$} & \multicolumn{2}{|c|}{$\begin{array}{l}\text { Thirteenth Plan } \\
\text { (2016-2020) }\end{array}$} & \multicolumn{2}{|c|}{$\begin{array}{l}\text { Fourteenth Plan } \\
\text { (2021-2025) }\end{array}$} \\
\hline & Health care & 2.65 & Health care & 5.44 & Health care & 4.37 & Health care & 5.66 & Health care & 5.15 \\
\hline 2 & Sports & 2.14 & Emergency & 2.83 & Emergency & 3.33 & Emergency & 3.27 & Emergency & 4.98 \\
\hline 3 & Living space & 1.01 & Sports & 2.01 & Sports & 1.84 & Sports & 1.91 & Sports & 2.18 \\
\hline 4 & Online & 0.86 & $\begin{array}{l}\text { Public } \\
\text { health }\end{array}$ & 1.84 & Public health & 1.37 & Disable people & 1.07 & Children & 1.88 \\
\hline 5 & $\begin{array}{l}\text { Disable } \\
\text { people }\end{array}$ & 0.81 & $\begin{array}{l}\text { Disable } \\
\text { people }\end{array}$ & 0.82 & Disable people & 1.35 & Children & 0.96 & $\begin{array}{l}\text { Public } \\
\text { health }\end{array}$ & 1.60 \\
\hline 6 & $\begin{array}{l}\text { Sports } \\
\text { facilities }\end{array}$ & 0.74 & Children & 0.77 & Children & 1.27 & Online & 0.88 & $\begin{array}{l}\text { Disable } \\
\text { people }\end{array}$ & 1.38 \\
\hline 7 & The elderly & 0.47 & Online & 0.76 & $\begin{array}{l}\text { Medical } \\
\text { supplies }\end{array}$ & 0.95 & Park & 0.83 & Pandemic & 1.06 \\
\hline 8 & $\begin{array}{l}\text { Medical } \\
\text { supplies }\end{array}$ & 0.40 & $\begin{array}{l}\text { Living } \\
\text { space }\end{array}$ & 0.73 & The elderly & 0.81 & Public health & 0.80 & Park & 1.02 \\
\hline 9 & Children & 0.38 & $\begin{array}{l}\text { Medical } \\
\text { supplies }\end{array}$ & 0.73 & Living space & 0.68 & The elderly & 0.79 & Online & 0.92 \\
\hline 10 & $\begin{array}{c}\text { Public } \\
\text { transportation }\end{array}$ & 0.31 & $\begin{array}{c}\text { Sports } \\
\text { facilities }\end{array}$ & 0.59 & $\begin{array}{c}\text { Public } \\
\text { transportation }\end{array}$ & 0.62 & $\begin{array}{l}\text { Medical } \\
\text { supplies }\end{array}$ & 0.59 & $\begin{array}{l}\text { Medical } \\
\text { supplies }\end{array}$ & 0.82 \\
\hline
\end{tabular}

Table 3. The Ten Most Frequent Terms and Their Frequency (\%oo). Source: Author.

NOTE: Frequency $(\% \circ)=$ Term frequency $/$ Total number of words in text

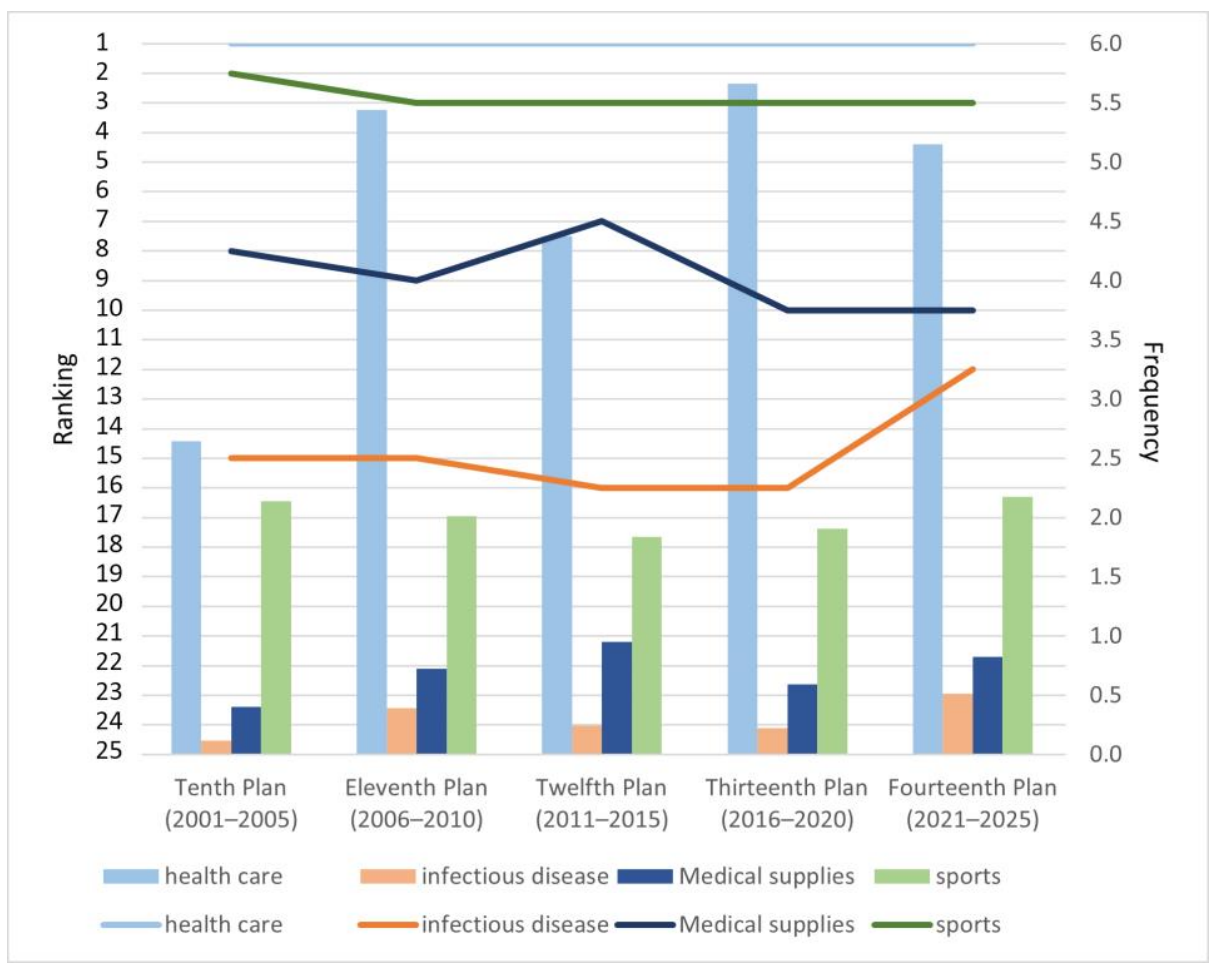

Figure 1. Four Terms with Stable Rankings and Their Frequency. Source: Drawn by author.

NOTE: Frequency $(\%$ oo $)=$ Term frequency $/$ Total number of words in text 


\begin{tabular}{|c|c|c|c|c|c|}
\hline & $\begin{array}{l}\text { Tenth Plan } \\
(2001-2005)\end{array}$ & $\begin{array}{c}\text { Eleventh Plan } \\
(2006-2010)\end{array}$ & $\begin{array}{l}\text { Twelfth Plan } \\
\text { (2011-2015) }\end{array}$ & $\begin{array}{c}\text { Thirteenth Plan } \\
(2016-2020)\end{array}$ & $\begin{array}{c}\text { Fourteenth Plan } \\
(2021-2025)\end{array}$ \\
\hline COVID-19 & ---- & ---- & --- & --- & 0.36 \\
\hline $\begin{array}{l}\text { Emergency } \\
\text { transportation }\end{array}$ & ---- & ---- & ---- & ---- & 0.01 \\
\hline Fever clinics & ---- & ---- & ---- & ---- & 0.02 \\
\hline $\begin{array}{l}\text { Medium or long- } \\
\text { term loans }\end{array}$ & 0.05 & 0.03 & ---- & 0.01 & 0.04 \\
\hline $\begin{array}{l}\text { Reduce rent and } \\
\text { interest }\end{array}$ & --- & --- & --- & ---- & 0.03 \\
\hline SARS & ---- & 0.18 & --- & ---- & ---- \\
\hline $\begin{array}{l}\text { Service in foreign } \\
\text { languages }\end{array}$ & --- & --- & ---- & ---- & 0.01 \\
\hline Stabilize posts & ---- & ---- & ---- & ---- & 0.01 \\
\hline
\end{tabular}

Table 4. Frequency (\%oo) of Special terms. Source: Author.

NOTE: Frequency= Term frequency/ Total number of words in text

Table 3 shows the ten most frequent terms and their frequency in Five-year plans of various periods. Combined with Figure 1 that shows four terms with stable rankings and their frequency, we can see that although the term "Health care" always comes in the first place, its frequency has become significantly larger after outbreak of SARS.

Comes to the second place, "Emergency" has been occupying this position except in Tenth Plan (20012005). In Figure 2 that shows five terms with unstable rankings and their frequency, we can see that the ranking of "emergency" is 14th in Tenth Plan (2001-2005). It is way below the second place. And its frequency is also far smaller than other years. Meanwhile, the frequency of "Emergency" in fourteenth Plan (2021-2025) is even significantly larger than Eleventh Plan (2006-2010), Twelfth Plan (2011-2015), and Thirteenth Plan (2016-2020).

Talking of the third place, according to Figure 1, there is no remarkable change of "Sports" neither in its ranking nor frequency. For the fourth and the fifth place, depending on Figure 2, we can see that both the ranking and frequency of "public health" has undergone a major increase after SARS and obvious growth after the occurrence of COVID-19.

Comes to the bottom five places: the situation of "Pandemic" is similar with "public health". While there is no obvious turning point of "Park". It's ranking and frequency have been growing steadily. About "medical supplies", its frequency slightly increased after both occurrence of SARS and COVID-19.

Among those terms ranked after the tenth place, both ranking and frequency of "Disease control and prevention" experienced significant growth after the occurrence of SARS and COVID-19. It can be seen In Figure 2. Finally, as Figure 1 shown, the frequency of "infection disease" slightly increased at the timing of both two outbreaks. Moreover, its growth of ranking after the occurrence of COVID-19 is more obvious than SARS.

\subsection{Discussion}

Based on the mentioned above, some conclusions can be drawn:

Firstly, after the occurrence of SARS and COVID-19, health care is taken more seriously. Depends on the transformation of word frequency of related terms, the development plan of pandemic prevention and control, public health emergency has been significantly affected. The differences between SARS and 
COVID-19 are mainly in the following aspects: 1) It can be said that China's modern emergency management system started since SARS, and it promoted the leap-forward development and transformation of China's emergency management system in public health emergencies. It especially can be concluded based on the change of term frequency of "health care" and "public health" after SARS outbreak. 2) While the ongoing COVID-19 is having a more profound and wider impact on China's public health emergency management system. It can be seen form the significant growth of word frequency of "emergency" in the Fourteenth Plan (2021-2025). As shown in Table 4, the uniqueness of "Emergency transportation", "Fever clinics", and "Service in foreign languages" which only appear in Fourteenth Plan (2021-2025) means that COVID-19 has been spreading more widely and reaching out to the community. It promoted the development plan of public health emergency management system with more details must be more thoughtful, and more comprehensive.

Secondly, the social and economic development plan relating to "infectious disease" and "medical supplies" is slightly affected by pandemic. The attention increased after two outbreak with a similar degree, but not by much. These two aspects are always be taken seriously as they are closely related to the daily life of civilians.

Thirdly, building Green Spaces and promotion of physical activity are also closely associated with everyday life. They have never been taken lightly. So, it is hard to say the stable increasing is caused by outbreak.

Fourthly, the COVID-19 outbreak has been going on for a long time and it's still lasting, and it's hard to tell when it will end. Hence, its impact on economy is much stronger than SARS. As shown in Table 4, the terms only appear in Fourteenth Plan (2021-2025) such as "Reduce rent and interest "and "Stabilize posts" illustrate the stronger impact. This is an important difference between SARS and COVID-19.

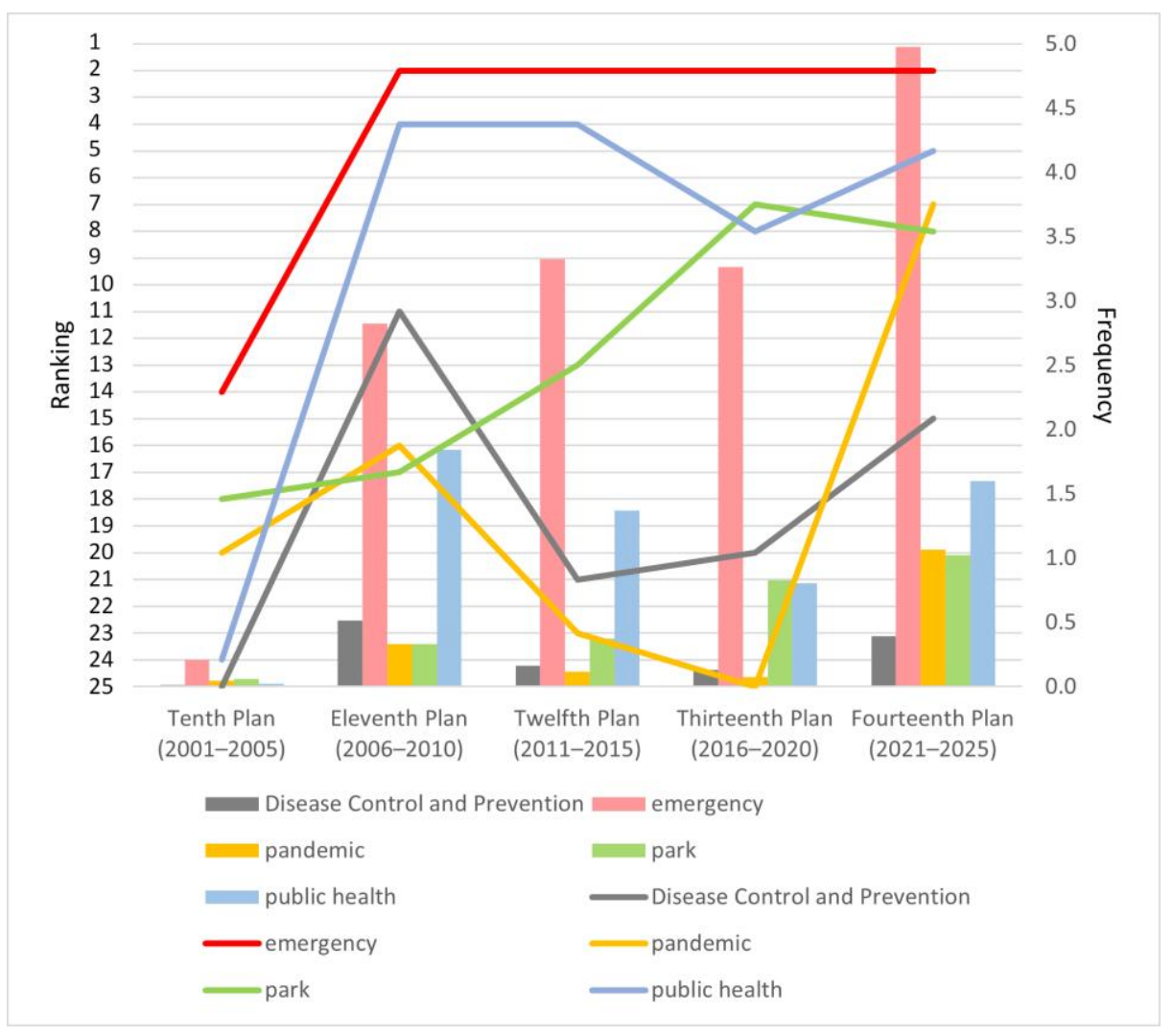

Figure 2. Five Terms with Unstable Rankings and Their Frequency. Source: Drawn by author.

NOTE: Frequency $(\%)=$ Term frequency/ Total number of words in text 


\section{Conclusion}

To sum it up, the system of China's modern public health emergency management started since SARS with a leapfrog development while has been promoting to more detailed and comprehensive during the COVID-19 outbreak. While the evolution of development plan relating to prevention and control of infectious diseases, medical supplies, building Green Spaces, and promotion of physical activity is not obviously. In addition, the economic policies released during the COVID-19 outbreak proposed various financial and banking supports and aid, such as "Interest discount and tax benefits" "Defer payment of taxes temporarily" "Return social security contributions appropriately" "Reduce loan interest rates "'Stabilize posts" "Increase credit loans and medium or long-term loans" "Extend or renew due loans" "Encouraged no or fewer layoffs" "Arrange working hours of workers flexibly" "Pay wages for employees staying at home"(Wu et al., 2021). All in all, the evolution of development plan about public health emergency management system and economic policy are more significant and is likely to have a profound effect on the future.

The accuracy of content analysis strongly relies on the method of word segmentation, vocabulary and stop words. In this study, there is still a lot of room for improvement regard to the above-mentioned. What's more, research based on "Outline of Five-Year Plan for Provincial Economic and Social Development" can provide a macro perspective. While city-level and specialized plan contain more details and specific information. For the further study, other text analysis will be applied; the vocabulary and stop list will be improved; and city-level and specialized plan will be considered as database.

\section{References}

CHINAZZI, M., DAVIS, J. T., AJELLI, M., GIOANNINI, C., LITVINOVA, M., MERLER, S., Y PIONTTI, A. P., MU, K., ROSSI, L. \& SUN, K. 2020. The effect of travel restrictions on the spread of the 2019 novel coronavirus (COVID-19) outbreak. Science, 368, 395-400.

EVENETT, S. J. 2020. Sicken thy neighbour: The initial trade policy response to COVID - 19. The World Economy, 43, 828-839.

HU, B., GUO, H., ZHOU, P. \& SHI, Z.-L. 2021. Characteristics of SARS-CoV-2 and COVID-19. Nature Reviews Microbiology, 19, 141-154.

LI, T., FANG, Y., ZENG, D., SHI, Z., SHARMA, M., ZENG, H. \& ZHAO, Y. 2020. Developing an Indicator System for a Healthy City: Taking an Urban Area as a Pilot. Risk management and healthcare policy, 13, 83-92.

LIANG, N., DU, J., LI, M. \& LUO, X. 2019. Economic Adaptability of the Development of Medical and Health Care and the Regional Differences in Hunan Province. Journal of Jishou University (Natural Sciences Edition), 40, 93.

PAN, X. \& ZHU, S. 2020. Development of Health Resources Allocation in Sichuan Province.

RAN, L., TAN, X., XU, Y., ZHANG, K., CHEN, X., ZHANG, Y., LI, M. \& ZHANG, Y. 2021. The application of subjective and objective method in the evaluation of healthy cities: A case study in Central China. Sustainable Cities and Society, 65, 102581.

SONGLIN, J., XI, L. \& ERKANG, F. 2020. Discussion on the Greenway Planning Strategy of Mountainous City. FOREST RESOURCES WANAGEMENT, 26.

SUN, M., XU, N., LI, C., WU, D., ZOU, J., WANG, Y., LUO, L., YU, M., ZHANG, Y. \& WANG, H. 2018. The public health emergency management system in China: trends from 2002 to 2012. BMC public health, 18, 1-9.

TAO, Y., ZHANG, F., SHI, C. \& CHEN, Y. 2019. Social Media Data-Based Sentiment Analysis of Tourists' Air Quality Perceptions. Sustainability, 11, 5070.

TAO, Y. G., ZHANG, F., LIU, W. J. \& SHI, C. Y. 2021. Tourists' Perceptions of Climate: Application of Machine Learning to Climate and Weather Data from Chinese Social Media. Weather, Climate, and Society, 13, 975-987. 
WANG, M. 2017. Analysis on Scale and Structure of Medical Expenditure of Chinese Government.

WANG, X., ZHANG, X. \& HE, J. 2020. Challenges to the system of reserve medical supplies for public health emergencies: reflections on the outbreak of the severe acute respiratory syndrome coronavirus 2 (SARS-CoV-2) epidemic in China. Bioscience trends, 14, 3-8.

WEBSTER, P. \& SANDERSON, D. 2013. Healthy Cities indicators--a suitable instrument to measure health? Journal of urban health : bulletin of the New York Academy of Medicine, 90 Suppl 1, 52-61.

WOLCH, J. R., BYRNE, J. \& NEWELL, J. P. 2014. Urban green space, public health, and environmental justice: The challenge of making cities 'just green enough'. Landscape and Urban Planning, 125, 234-244.

WU, J., WANG, K., HE, C., HUANG, X. \& DONG, K. 2021. Characterizing the patterns of China's policies against COVID-19: A bibliometric study. Information Processing \& Management, 58, 102562.

YANG, Y., PENG, F., WANG, R., GUAN, K., JIANG, T., XU, G., SUN, J. \& CHANG, C. 2020. The deadly coronaviruses: The 2003 SARS pandemic and the 2020 novel coronavirus epidemic in China. Journal of autoimmunity, 109, 102434.

YIN, K., ZHAO, Q. \& ZHAO, Y. 2010. Reflection of the application of urban forest ecological service to landscape planning. Advances in Earth Science, 25, 444-450.

YUN, W. \& YU, Z. 2011. Ecological landscaping strategy of rural land consolidation in China. Transactions of the Chinese Society of Agricultural Engineering, 27, 1-6.

ZHANG, S., LIU, Y. \& HUANG, D.-H. 2021. Understanding the mystery of continued rapid economic growth. Journal of Business Research, 124, 529-537. 